NOTICIÁRIO

\begin{abstract}
DEFESA DA TESE APRESENTADA AO DOUTORAMENTO NA CADEIRA DE LINGUA E LITERATURA INGLESA DA FACULDADE DE FILOSOFIA, CIRNCIAS $\mathrm{B}$ LETRAS DA UNIVERSIDADE DE SAO PAULO PELO LICENCIADO HIGINO ALIANDRO
\end{abstract}

O Lic. Higino Aliandro, que desde 1945 vem exercendo a função de primeiro assistente da Cadeira de Lingua e Literatura Inglésa e Norte-Americana, apresentou-se ao doutoramento no dia 9 de junho de 1950 , com a tese intitulada "John Donne no movimento literário metafísico". A atividade do cente do dr. Aliandro como professor de lingua inglêsa começou em 1931 . Posteriormente dedicou-se também ao ensino das literaturas inglêsa e americana. Foi secretário-executivo da Únião Cultural Brasil-Estados Unidos de 1945 a 1947. Em 1946, com bolsa de estudos, freqüentou a Universidade de Michigan em Ann Arbor, nos Estados Uniảos da América do Norte. No começo do corrente ano foi encarregado da direção da Cadeira de sua especialldade na Faculdade de Filosofia, Ciências e Letras da Universidade de Săo Paulo.

Conhecedor dos claros existentes neste ramo do ensino, quis contribur com seu trabalho ao preenchimento de um déles: a divulgação da obra e do pensamento de John Donne, pouco conhecido entre nós, e de muita importância para os autores modernos. A meta foi alcançada plenamente. Aceitando o plano de trabalho que the sugeriu o prof. Kenneth J. Swann, titular da cadeira em questão até 1947, e enfrentando a grande responsabilidade de tratar tão intrincado tema, em vista da impossibilidade de obter tôda bibliografia atinente a tal estudo (grande parte das obras indicadas não as pode obter, ou por estarem exgotadas, ou por estarem inaccessiveis nas bibliotecas inglêsas), procurou o dr. Aliandro pôr em evidéncia os seguintes temas: a) John Donne, sua biografia nos fatos elucidativos de sua obra; b) os aspectos gerais dessa obra, quer em prosa, quer em verso; c) o movimento metafísico seiscentista, onde especialmente focaliza Donne, seus principais discipulos e Shakespeare; d) as imagens, os conceitos e as atitudes mais caracterisadoras da poesia de Donne.

A intenção da tese, as dificuldades bibliográficas, os quatro tẹmas acima relacionados, nos são referidos em um prefácio onde, também, nos apresenta Tohn Donne, autor inglês. A tese contém 106 páginas datilografadas, assim distribuidas: 1)! Prefácio; 2) Indice: 3) Biografia; 4) Obra: 5) O movimento literário metafísico; 6) Conclusōes; 7) Notas; 8) Cronologia donniana; 9) Os aspectos de "Canções e Sonetos"; 10) Bibliografia.

$\mathrm{Na}$ pormenorisada biografia destacam-se, principalmente, os seguintes fatos elucidativos da obra donniana: a) segundo afirmação de Donne, a Jonson, as cançðes, as elegias e as principais sátiras já se encontram escritas antes dos 25 anos; nos poemas desta fase notam-se abundantes metáforas de cunho juridico, o que demonstra o influência do Direito sóbre o espirito do poeta: b) de 1601 a 1615 a poesia e a vida de Donne são uma adulação inteligente a patronos reals ou prováveis; c) os fatos determinantes da conversăo de 
Donne, de católico para anglicano, e a conseqüente ordenação como pastor, conversão esta de grande importância porque sugeriu ao próprio poeta a divisão de sua vida em duas partes, a secular ou a de Jack Donne e a religiosa ou a do Dr. Donne; mesmo condizendo com a distinção apontada peld poeta, esta divisão não revela a realidade, pois Donne permanece o mesmo homem restas diferentes fases, tendo-se operado em seu espirito apenas uma transmutação do objeto de scus desejos; d) 1616 a 1630 escreveu os famosos sermões e os poemas sacros, vindo a falecer em 1631 .

Ao estudo da obra de Donne dedica 46 páginas, nas quais examina as fases literárias da vida do poeta, com base nos textos e na biografia, sugerindo para as mesnas o seguinte quadro-tentativa:

$$
\begin{aligned}
& \text { 1." fase } \\
& \text { (a) poeta } \\
& \text { ( } \pm \text { 1593-1601) } \\
& \begin{cases}\text { a) } & \text { poeta } \\
\text { b) } & \text { prosador }\end{cases} \\
& \begin{array}{l}
2 . \text { fase } \\
( \pm 1601-1614)
\end{array} \\
& \text { a) prosador austero } \\
& \text { b) epistológrafo } \\
& \text { 3." fase } \\
& \text { c) poeta artificial }
\end{aligned}
$$$$
\text { 1. Cançōes e sonetos }
$$$$
\text { 2. Sátiras e elegias }
$$$$
\text { 3. Epigramas }
$$

Apoiando-se na correspondenncia do poeta, estabelece os elos psicológicos entre a vida de Donne e suas obras. As obras em prosa, o pregador $e$ as cartas são sucessivamente apresentadas antes de uma visăo de conjunto da poesia donniana, pois o que realmente interessa à tese è o poeta. Em "Paradoxes and Problems" e "Ignatius his Conclave" ou "His Inthronisation in a late Election in Hell", destaca o prosador satirico e violento que na segunda obra citada se mostra contrário aos jesuitas. No "Pseudo-Martir" salienta o controversista, concluindo, contràriamente ao título, tratar a obra do ponto dé vista político e jurídico, da luta entre a autoridade civil e a eclesiástica. "Biathanatos", um estudo a respeito do suicidio, a que alguns críticos dão importância autobiográfica, seria melhor interpretado como uma justificação da idéia do suicidio, interpretação esta apoiada em cartas de Donne que revelam - pensamento da morte e permitem fixar a época em que a obra foi escrita.

Apesar do valor dessas obras e do grande e profundo conhecimento nelas revelado, a fama do autor, como prosador, repousa nos sermōes. Após breve notícia sôbre o pregador, o epistológrafo é apresentado através de uma de suas próprias cartas, em que faz o elogio da correspondência. São conhecidas cêrca de 160 cartas. Enviadas a amigos e patronos, escritas com a finalidade de atingir a posteridade, revelam nâo só a personalidade brilhante e insolente de Donne, como também sua sabedoria e erudição. As cartas são utilizadas e interpretadas através de tôda a tese.

A visão de conjunto da poesia donniana segue de perto o critério cronológico de composição dos gêneros literários pelo poeta. Este critério, que aparece adotado nas duas primeiras ediçōes (1633-1635) da obra poética de Donne, é o seguinte: Canções e Sonetos, Epigramas, Elegias, Epitalâmios, Sátiras, Cartas a Diverses Pessôas. Elegias funerárias, O Progresso da Alma e Poemas Divinos.

Três divisões são estabelecidas para a poesia de Donne: a) amorosa; b) metafisica; c) satirica.

"Cançōes e Sonetos" e as elegias exemplificam a poesia amorosa, bastante realista. Do estudo dos pormenores dêsses poemas resultou uma tentativa de classificacãn das "Cançōes e sonetos" segundo o critério de três aspectos nelas notado: $10^{\circ}$ ) cinismo e insoléncia apaixonada, isento de lamenta. 
ções petrarquianas; $20^{\circ}$ ) desesperança e adoração, tipicas do petrarquisıo platónico da época: artificialismo; $3 .^{\circ}$ ) menos artificialismo do que no segundo aspecto, mais pureza do que no primeiro, sinceridade, lealdade e alegria do amor correspondido.

Os poemas satiricos e metafísicos constituem a maior parte da obra poética de Donne e inumeros déles são examinados nos seus pormenores. As cartas versificadas $e$ as elegias funerárias, que caracterizam os anos centrais da existencia do poeta, refletem um periodo artificial. Para provar esta conclusāo, muitas delas são, também, estudadas nos seus pormenores.

Juntamente com o exame dos aspectos caracteristicos dos poemas, ocorre um exame dos temas. "The First Anniversary" e "The Second Anniversary". elegias funerárias que fazem parte de dois poemas longos. "The Anatomy of the World" $e$ "Of the Progress of the Soul", são examinadas minuciosamente do ponto de vista do tema: a contemplação do tempo e da morte. Os poemas sacros "On the Annunciation and Passion falling upon 'one day", "The Litany", "La Corona" e "Holy Sonnets" são citados e comentados de um ponto de vista psicológico; neles o objeto da afeição do poeta mundano encontra-se transmutado.

Uma análise acurada dos poemas de Donne pós em relevo: a) os seus extremos poćticos: lirico-amoroso, ora cinico, ora satirico, quase sempre irônico; satirico; mistico, aqui aparecendo também o cunho irônico; b) seu rompimento com a tradição petrarquiana na forma $e$ no tom suave convencional de expressão; sua necessidade de expressão pessoal e viril dá novo impulso à poesia inglêsa; c) a transformação que se passava em seu espirito quanto ao objeto da afeição; d) gósto por temas repetidos e preferência por determinadas palavras aplicadas a certas qualidades de pessôas definidas. Um estudo comparado dêsses temas e dessas palavras ocorrentes em textos diversos, permitiu relacionar os poemas e descobrir a quem se destinavam, ou quem é a inspiradora dos versos.

A situação de Donne no movimento literário metafísico foi desenvolvida em 37 páginas, abrangendo os seguintes tópicos: a) definição do movimento; b) Shakespeare metafísico; c) as imagens e os conceitos na poesia isabelina: Donne e Shakespeare como poetas metafisicos; d) as imagens $e$ os conceites de Donne; e) Poemas divinos.

No desenvolvimento dêstes tópicos salientam-se:

a) 1. A poesia metafísica é a poesia da agudeza (wit), considerada não só como percepção aguda das analogias, mas também como viva conviç̧ão do fato de que a atitude clara para com uma dada situação não é a única possivel. Escrevendo seus poemas sôbre assuntos incomuns, teria forçosamenté os poetas metafísicos de torná-los repletos de imagens, mas imagens incomuns, portanto dificeis. Ulsam paradoxos, similes, hipérboles e metáforas, numa palavra "conceitos" esquisitos. Realizam o equilibrio perfeito entre o intelecto e a emoção. 2. Os conceitos de Donne comparados aos de seus discipulos G. Herbert, Richard Grashaw, Robert Herrick. Thomas Carew e Henry Vaugham.

b) 1. Aproximação entre o desenvolvimento do estilo de Shakespeare e o de Donne. 2. A crescente complexidade do estilo shakespeariano revela o mesmo exercicio mental que os metafisicos tanto se compraziam em obrigar os leitores a praticar. 3. Os conceitos de Shakespeare ein "As you like it", "T'welfth Night" e nos "Sunnets". Os conceitos de Shakespeare profundamentc engenhosos; os de Donne repletos de erudição.

c) 1. Os processos de imaginação poética. 2. Shakespeare e Donne, poetas metafísicos, através de uma comparação entre as caracteristicas diferenciadoras de suas imagens e conceitos.

d) 1. O caráter essencialmente funcional das metáforas e conceitos nos poemas metafisicos. 2. A aplicação do vasto conhecimento de Donne na poesia pode ter sido espontânea. As argumentações, as comparaçōes na poesia como produto da emoção e da erudição do poeta. 3. A metáfora ligada 
a agudesa do intelecto (wit); os vários tipos de agudeza servindo para exprimir: a) precisão, b) concentração, c) cunho irônico. 4. Enumeração dos diferentes cunhos irônicos revelados pelas imagens e conceitos das "Cansóes e sonetos".

e) 1. O cunho irônico incompativel com à poesia religiosa. 2. A agudeza e o cunho irônico aparecem nos poemas mais solenes de Donne. 3. Os sonetos X e XIV examinados dêste ponto de vista. 4. A união mistica-metafísica; equilibrio entre intelecto e emoção. 5 . Diferença entre a mistica inglêsa, a espanhola e a portuguêsa.

Terminado o acurado estudo e a avaliação da obra poética de Donne, nas "Conclusőes" insiste o dr. Aliandro nos pontos de vista apresentados no prefácio e no decorrer da tese: 1) originalidade impressionante do poeta; 2) seu rompimento com a tradição petrarquiana em fundo e forma, dando origem à lírica metafísica; 3) Petrarca ainda aparece na poesia donniana, especialmente quando dedicada a uma dama, mas sempre alterado; 4) foi o primeiro satírico da inspiração clássica; 5) os sermões e a poesia são as partes mais importantes da obra donniana; dentro da escola metafisica seiscentista destacam-se pela inspiração e pela riqueza e novidade das imagens e dos conceitos. 6) os conceitos e as imagens de Donne distinguem-se pela erudição; 7) há na poesia donniana as seguintes notas: precisão, concentração, ironia; 8) a nota de ironia aparece sob os mais variados aspectos e atitudes 9) nos poemas liricos observa-se uma tendência para a unidade das seguintes atitudes: cinismo artificial com laivos de ternura, contemplação do tempo e da morte, unificação destas atitudes e climax no poema "The Extase"; 10) a nota dominante dos poemas líricos, a ironia, salienta-se nos poemas divinos quase com a mesma intensidade; 11) por meio do cunho irônico no jogo das imagens, dos conceitos, das metáforas, dos paradoxos, das hipérboles, das antíteses. Donne procura atingir o enobrecimento e excede a todos os discipulos pela inteligência conceptualista e sinceridade da emoção.

A comissão examinadora constituida pelos professores Pedro de Almeida Moura, Fidelino de Figueiredo, Emile G. Léonard, Leonard S. Downes e Geoffrey Wile fol unânime em ressaltar a oportunidade e o valor informativo da tese para o público não especializado, a probidade crítica revelada na sua realização e o espirito de cooperação do homem que recebe sugestões. As observaçóes dos examinadores referiram-se, principalmente, a certos pormenores biográficos, aos pontos originais e à forma da tese.

Iniciando a arguição, o prof. Fidelino de Figueiredo apresentou as seguin tes objeçōes: 1. Para a grande critica inglêsa o interêsse da tese não é o de uma especialização de assunto. 2. A aproximação original de Donne e Shakespeare mais desenvolvida teria dado ao trabalho tôda originalidade de uma tesc. 3. A aproximação da mística inglésa e da mística ibérica (Frei Tomé de Jesus, Samuel Usquue e San Juan de la Cruz) destacando: a) diferença entre filosofia e poesia; b) diferença entre a mistica inglêsa, portuguêsa e espanhola; c) estudo mais profundo da mistica de Shakespeare, teria levado o candidato a uma tese do mais alto valor comparativo e critico. 4. Ausência da recapitulação da critica inglêsa quanto ao assunto destas duas últimas observaçôes. 5. O estudo original das imagens e conceitos da poesia inglêsa não é mais importante do que o desenvolvimento das duas aproximaçōes apontadas na tese. Humberto de Campos já realizou êste trabalho em "O concelto e a imagem na poesia brasileira". 6. Como valores positivos da tese destacou: a) as qualidades de uma Memória, realizada com támanha sinceridade critica, que atrai a atenção; b) apresenta muitas noticias de interêsse.

Respondendo ao prof. Fidelino dé Figueiredo, pôs o candidato em evidência os seguintes pontos: 1. Se tese é um estudo comparativo, a defesa de uma idéia, uma monografia, tese também è o trabalho que apresenta originalidade. Sáo originais o capitulo "Imagens e conceitos da poesia isabelina" e a classificação apresentada para melhor comprcensão dêles. Na literatura inglêsa autor nenhum ainda, tratou dêste assunto. 2. Uma aproximação tão intima 
entre Shakespeare e Donne foi feita, que permitiu destacar pormenorisadamente as caracteristicas shakesperianas e donnianas. 3. Não existe em Portugal uma mística poética, mas sim a prosa mistica de Frei Tomé de Jesus e Samuel Usque; a mistica espanhola com San Juan de la Cruz é um estado de exaltaçăo multo diferente da serenidade contemplativa inglêsa, proveniente do equilibrio absoluto entre o intelecto e a emoção. O estudo comparativo profundo da mistica inglêsa e ibérica não foi feito por constituir assunto para outra tese. 4. As obras criticas não são possiveis de se obterem fora da Inglaterra. 5. Humberto de Campos não apresenta uma classificação elucidativa em "O conceito e a imagem na poesia brasileira", mas, sim, uma compllação de poemas que ilustram títulos genéricos, tais como a Rosa, A Amor, a Morte. etc.

Com a paiavra, o prof. Emile Léonard apresentou as seguintes objeçбes: 1. Pequena a proporção da história geral e eclesiástica em relação à importåncia histórica e religiosa do poeta; Donne, poeta e pastor anglicano, exerceu influéncia sôbre outros ministros, como, por exemplo, os irmãos Wesley. 2. A obra "O Pseudo-Martir" como chave para compreensão da conversão religiosa de Donne é mais valiosa do que como exposição dos conceitos não condizentes com o martirio, ou, como sátira violenta contra os jesuitas. 3. A falta de sinceridade na conversão de Donne, provada pelo fato de descender o poeta de mártires católicos, é argumento fraco, poịs naquele tempo era comum a passagem de membros da Igreja Romana para o Anglicanismo. 4. Um estudo dos poemas isolados dos sermóes náo é completo, porque o pregador e o poeta săo inseparáveis: as caracteristicas dos sermōes são as mesmas dos poemas. 5. O estudo dos poemas divinos, feito em quatro páginas apenas $(50-54)$ é insuficiente. 6. O conceitualismo aparece em todas as misticas dos paises protestantes, nåo sendo uma característica extraordinária da poesia donniana. 7 . Os poemas religiosos e conceitualistas da primeira metade do século XVII em França deveriam ser incluidos; a obra de Ajbert Schmidt impðe-se neste assunto.

As tais objeções respondeu o dr. Aliandro: 1. Um estudo mais profundo da história geral e eclesiática teria conduzido a outra tese. "O PseudoMartir" visto por uma católico-romano tem significaçăo diferente de quando visto por um protestante. 3. Entre os parentes de Donne sacrificados pela perseguiçăo anglicana, conforme relàção constante da própria tese (nota 9), figu ram sua mãe, falecida no exílio, e o irmão que morreu na prisão, apenas por ter dadd abrigo a dois jesuitas; êstes acontecimentos, de tanta significação para o poeta, ñ̃o o levariam, na certa, a entrar por convicçáo na Igreja Angllcana. 4. Que as caracteristicas dos sermōes são as mesmas dos poemas, isto está revelado na tese: esta, porém, foi baseada sôbre a poesia e não sôbre a prosa. 5. O estudo dos poemas divinos compreendido entre as páginas 50 (inclusive) e 54, portanto 5 páginas, é acrescido, na parte final da tese, de outras 5 páginas $\left(86-89 .{ }^{n}\right)$; além disto, tôda a parte final, desde o "Movimento Literário Metafísico", trata do assunto. 6. O conceitualismo na poesia de Donne é ressaltado por ser um dos pontos originais da tese, uma tentativa de classificaçáo das imagens e conceitos donnianos. 7. Os poemas religiosos conceitualistas franceses náo foram incluidos, porque năo era finalidade da tese um estudo comparativo profundo, o que daria assunto para outro trabalho.

Foram as seguintes as objeçōes do prof. Leonard S. Downes: 1. Maior interêsse compensador teria resultado do esfôrço da tese orientado no sentido da influência da mistica espanhola sôbre a inglesa. 2. Estudo insuficiente do fundo histórico-religioso do tempo. 3. A viagem de Donne à Espanha. o contacto con a Inquisição, contribuiram para que mudasse de igreja. 4. A sinceridade da conversão provada pelo que Donne chamou de religiãd corrupta, após o contacto com a Inquisição. 5. "O Pseudo-Martir" deve ser interpretydo à luz dos acontecimentos contemporâneos. 6. Certos aspectos literários deveriam ser ressaltados com o devido valor dentro da época e não como extraordinários. As comparações eram um divertimento da época. 7. É uma carateristica tipica do anglicanismo o equilibrio entre a fê e a razáo, ressaltado 
como extraordinário na poesia donniana. 8. A pesquisa das expressōes que levaram à descoberta das pessoas inspiradoras dos versos não tem base sólida, pois estas expressões eram parte do vocabulário geral da época, como a palavras bomba atômica, avião. locomotiva, fazem parte do vocabulário de hoje.

Com os seguintes argumentos se defendeu o Lic. Higino Aliandro: 1. e 2. Orientar o esfôrço da tese no sentido da influéncia da mistica espanhola sôbre a inglêsa, bem como ampliar o fundo histórico-religioso, seria fugir ao plano pré-fixado e desenvolver outras teses. 3 e 4. $O$ contacto com a Inquisição, como fator determinado da maior ou menor sinceridade da conversão, nảo prevalece sôbre o fato dos parentes mais próximos de Donne terem sido sacrificados pela perseguição anglicana. 5. Não era intenção da tese uma interpretação do "Pscudo-Martir". 6. Os aspectos literários ressaltados como extraordinários, como as comparaçōes, o foram em função do estudo das imagens e conceitos. 7. Donne introduziu o equilibrio entre a fé e a razão, ou melhor, entre o intelecto e a emoção, ou, ainda, entre a razão e a sensibilidade, na lirica inglesa; êste equilibrio não é caracteristica tipica da fé anglicana. 8. A intenção foi levantar uma estatistica das expressōes ocorridas nos poemas de Donne e não nos de outros poetas do tempo; tal estatistica não tem valor para os outros poetas.

Arguiu, a seguir, o prof. Geoffrey Wile: 1. Os motivos da mudança de igreja precisam ser mais esclarecidos. 2. $\mathrm{O}$ sentido dado ao verso "Be the Seas Water, and the Land all sope" ("Fôssem tôda a água da mar e tôda a terra sabão") não é admissivel em virtude da posição da virgula. 3. "A certain modern intimate quality" é uma frase de Pierce Smth sôbre as caracteristicas da poesia donniana, que o candidato poderá comentar, embora fugindo ao assunto da tese.

Foram estas as respostas do candidato: 1. A passagem do catolicismo para o anglicanismo não fol repentina; um periodo de estudos teológicos a precedeu; os interêsses $e$ as ambiçōes de Donne, em grande parte, justificaram a resolução. Não houve, porém, uma conversão verdadeira, uma transmutação completa de natura, mas apenas uma transmutação do objeto de seus desejos. - 2. O verso citado ("Be the Seas Water. and the Land all sope"), apesar da posição da virgula, só admite o sentido dado, pois o outro sentido plausivel, isto é "fôssem os mares de água" seria um pleonasmo ridiculo; a virgula deve estar errada e não o sentido atribuido ao verso. 3. Os poetas modernos, como Yeates, T. S. Elliot são donnianos, metafisicos pelos seus processos intelectuais. Nisto consiste a qualidade moderna de Donne.

Finalisando, o prof. Pedro de Almeida Moura dividiu suas observaçôes em externas e internas. Externast 1. O titulo da tese não condiz com ela. "Redescobrimento de Donne" seria melhor denominação para um trabalho que pretende divulgar um autor importante do pasado. 2. A forma está sacrificada na lingua portuguêsa; a estrutura externa prejudicou a interna; deficiência de sinonimia. 3. A rudeza de certas expressōes nas traduçōes apoéticas; o lado estético foi negligenciado; traduçōes poéticas teriam evitado o obceno na Arte, como fêz Baudelaire que, traduzindo um poema inspirado na reputação duvidosa de uma mulher, usou expressões tão suaves que a reputaçáo se tor. „ou boa. Internas: 1. O poeta deveria ter sido destacado dentro de um quadro geral da Literatura Inglêsa e não isoladamente. 2. $\mathrm{O}$ aspecto mais ressaltado do poeta, o mundano, não tem interêsse vital. 3. $O$ vocabulário específico de Donue, apenas referido em partes diferentes da tese, deveria ser objeto de estudo mais desenvolvido.

Respondendo ao seu último arguidor, firmou-se o dr. Aliandro nos se. guiates pontos: Consideraçōes externas - 1. A importância da divulgação de Donne justificarse não só pelo valor intrínseco do poeta, como também pela escola a que deu origem; daí o título da tese. 2. A forma na lingua portuguêsa fol sacrificada a uma tradução honesta dos textos inglêses; a sinonimia envolve uma questáo pessoal, o estilo. 3. As traduções dos poemas foram feitas se- 
gundo o critério do tradutor e não do traditorił traduçôes apoéticas, mas fiéis ás imagens e conceitos do poeta foram preferidas às traduções poéticas, que afastariam desta finalidade; a rudeza de certas expressões são explicáveis tendo-se em vista a fidelidade ao texto inglês, à idéla do poeta; Donne era muito sincero nos seus poemas e não recuava com eufemismos; a mesma atitude foi adotada na interpretação e tradução dos poemas. Além disto, as teorias sôbre - obceno na Arte são muito discutiveis. Considerações internas - 1. A intenção da tese foi focalizar Donne no movimento literário metafísico. $O$ aspecto mundano foi ressaltado em consequiência da pesquisa sôbre as inspiradoras dos poemas. 3. Sem dúvida alguma a tese poderia ser ampliada com um estudo desenvolvido do vocabulário de Donne, mas éste trabalho pela sua natureza filológica, não faz parte dos objetivos de uma tese literária.

Como se pode aduzir das observações dos examinadores e da satisfatória defesa do candidato, a tese é muito oportuna e foi plenamente aprovada. Além de contribuir para o enriquecimento do patrimônio literário universitário, veio, especialmente, facilitar aos estudosos da Literatura Inglêsa a compreensão de uma das suas figuras mais complexas. de tanta significação para os problemas literários modernos.

EDNA CHAGAS CRUZ.

\section{DEFESA DE TESE APRESENTADA A CADEIRA DE GEOGRAFIA DO BRASIL DA FACULDADE DE FILOSOFIA, CIENCIAS E LETRAS DA UNIVERSIDADE DE SAO PAULO, PELO LICENCIADO JOSÉ RIBEIRO DE ARAUJO FILHO}

Realizou-se no dia 6 de junho do corrente ano a defesa de tese de doutoramento do Lic. José Ribeiro de Araujo Filho, $10^{\circ}$ assistente da Cadeira de Geografia do Brasil, da Faculdade de Filosofia, Ciências e Letras da Un!versidade de São Paulo.

O candidato aprovado com distinção, com a média 9,16 fol examinado pela seguinte Banca: Prof. Dr. Aroldo de Azevedo, Professor Catedrático de Geagrafia do Brasil - Presidente; Prof. José Verissimo da Costa Perelra, Geógrafo Especializado do Conselho Nacional de Geografia e Chefe da Secção Centro-Oeste do mesmo Conselho; Prof. Dr. Alfredo Ellis Junior, Professor Catedrático de História do Brasil da Fac. de Filosofia, Ciências e Letras da Universidade de S. Paulo; Prof. Dr. João Dias da Silveira, Professor de Geografia Fisica da mesma Faculdade; e, Prof. Dr. Ary França, professor da Cadeira de Geografia Humana da mesma Faculdade - todos membros da Comissão Examinadora.

A tese do candidato inscrito, versou sôbre "A baixada do Itanhaém; estudo de geografia regional", sôbre a qual entáo foram realizados amplos e interessantissimos debates que serviram para demonstrar $\circ$ alto grau de cultura geográfica ministrada na Faculdade de Filosofia, Ciências e Letras da Universidade de S. Paulo.

Transcrevemos, a seguir, o Sumário da tese em apreço:

Introdução: As razōes da escolha do tema.

I - A baixada do Itanhaém e seu quadro natural. O litoral paulista e a baixada do Itanhaém. O relévo e a costa. A rêde fluvial. Caracteristicas do clima. A sub-regiăo costeira. A baixada interior. $O$ quadro natural e a vida humana.

II - Povoamento e população - As condiçōes geográficas e o povoamento. O povoamento antigo. A populaçáo atual. Os tipos humanos. O caiçara, personagem-tipo da regiáo. $O$ homem do bananal. 